\title{
BODY SIZE, POPULATION METABOLISM, AND HABITAT SPECIALIZATION AMONG LARGE AFRICAN HERBIVORES
}

Large species generally occur at lower population densities than small species but, being larger, use more energy per individual. The balance between population density and energy use per individual determines how evenly community resources are shared by species of different size. Analyses of large data sets, covering a wide range of body sizes, have found that population metabolism (the product of population density and energy use per individual) scales either neutrally (Damuth 1981, 1987) or negatively (Peters 1983) with body mass. However, different scaling relationships may occur in certain communities within specific biogeographic regions. Brown and Maurer (1986) found that population metabolism scales positively with body mass among North American land birds, granivorous desert rodents, marine fishes, and perennial desert plants. A comprehensive study of the relationships between mammalian population density and body mass (Peters and Raelson 1984) indicates that population metabolism scales positively with body mass among "smaller tropical" herbivores $\left(\alpha M^{0.26}\right)$, "larger tropical" herbivores $\left(\alpha M^{0.45}\right)$, and "larger tropical" carnivores-omnivores $\left(\alpha M^{0.28}\right)$ but not among North American species (herbivores, $\alpha M^{0.09}$; carnivores-omnivores, $\left.\alpha M^{-0.39}\right)$.

We present results confirming that among African savanna herbivores, population metabolism scales positively with body mass. That is, larger species use a disproportionately larger share of local resources. We also present a hypothesis to explain this, on the basis of patterns of habitat use.

We analyzed census data for mammalian herbivores $(\geq 4 \mathrm{~kg}$ ) from 11 African national parks or wildlife reserves within the savanna biome. Areas varied from 75 $\mathrm{km}^{2}$ to $19,500 \mathrm{~km}^{2}$. Population metabolism was calculated as the product of mean population density, mean individual body mass, and mass-specific metabolic rate (assumed to scale as $M^{-0.25}$; Kleiber 1961). The combined data from these parks show that population metabolism increases significantly with body mass (table 1). However, a tendency to undercount smaller species could have influenced this result. Hence, we also examined ungulate populations estimated for the Umfolozi Game Reserve in South Africa, where aerial census data were corrected with intensive ground-based counts. A similar relationship between population metabolism and body mass was found. Finally, we considered the highest local densities reported from specific studies in areas favored by each species. Our analysis (table 1) shows that, among large herbivorous species in African savanna ecosystems, population metabolism increases approximately in relation to $M^{\mathbf{0 . 4 5}}$. This relationship is confirmed by Damuth's (1987) data, in which population metabo- 
TABLE 1

Relationships between Population Metabolism and Body Mass for Large African Herbivores

\begin{tabular}{|c|c|c|c|c|c|c|c|c|}
\hline \multirow[b]{2}{*}{ Scale } & \multirow{2}{*}{$\begin{array}{l}\text { RESEARCH } \\
\text { AREA* }\end{array}$} & \multirow{2}{*}{$\begin{array}{l}\text { AREA } \\
\left(\mathrm{km}^{2}\right)\end{array}$} & \multirow{2}{*}{$\begin{array}{l}\text { BoDY-MASS } \\
\text { RANGE (kg) }\end{array}$} & \multicolumn{5}{|c|}{ Regression Statistics } \\
\hline & & & & $b$ & SE & $a$ & $r$ & $n$ \\
\hline $\begin{array}{l}\text { Savanna } \\
\text { biome }\end{array}$ & $\begin{array}{l}11 \text { conservation areas } \\
\text { (combined) }\end{array}$ & 65,000 & $10-2100$ & 0.40 & 0.16 & 0.84 & 0.65 & 25 \\
\hline Regional & $\begin{array}{l}\text { Umfolozi Game Reserve, } \\
\text { S. Africa }(1970)\end{array}$ & 450 & $20-1350$ & 0.51 & 0.21 & 0.85 & 0.72 & 13 \\
\hline Local & $\begin{array}{l}\text { Various single-species } \\
\text { studies }\end{array}$ & - & $4-2100$ & 0.46 & 0.14 & 1.75 & 0.73 & 25 \\
\hline
\end{tabular}

NoTE.-Statistics are for the relationship between population metabolism $(E)$ and body mass $(M)$ according to the least-squares-regression equation $\log E=a+b(\log M)$; $\mathrm{SE}$, standard error of the slope $b ; r$, correlation coefficient; $n$, number of species.

* Sources listed in Owen-Smith 1988.

lism among large African herbivores $(\geq 10 \mathrm{~kg})$ in grassland and savanna regions scales in relation to $M^{0.43}$ (Damuth, unpubl. data). Thus, a 10-fold increase in species body mass would be associated with an almost threefold increase in resource use.

Brown and Maurer suggested several advantages of large body size that may result in large species' dominating resource allocation, including dominance in interspecific aggression, better predator evasion, and enhanced ability to use lowquality foods. However, aggressive competition for food is rare or absent among ungulate species, which instead frequently associate together, deriving mutual benefits in terms of predator avoidance (Jarman 1974; Sinclair 1985). In fact, feeding by larger species may even enhance food availability for smaller ungulate species (Vesey-Fitzgerald 1960; Bell 1971). Furthermore, diminished predation levels occur only among the very largest species, exceeding about $1000 \mathrm{~kg}$ in body mass (Owen-Smith 1988). Among large herbivores, enhanced tolerance for lowquality foods (Bell 1971; Jarman 1974) arises from the allometry of the metabolic rate-gut capacity relationship (Demment and van Soest 1985). We propose that this relationship also enables larger species to spread more evenly through ecosystems by feeding productively in habitats that are less suitable for smaller species.

We compared patterns of habitat use by three species of browsing ruminant: steenbok (Raphicerus campestris); kudu (Tragelaphus strepsiceros); and giraffe (Giraffa camelopardalis). These species were selected because of their large differences in body mass $(11 \mathrm{~kg}, 180 \mathrm{~kg}$, and $800 \mathrm{~kg}$, respectively) together with their similarities in food resource base (foliage of woody plants and forbs) and distribution (coexisting in most African savanna regions). Comparative habitat use was investigated using data from a 3-year study conducted in the central Kruger National Park, South Africa (du Toit 1988). For each species, proportional use of each of the 14 habitat types (vegetational communities) in the $160-\mathrm{km}^{2}$ study area was calculated as

$$
p_{\mathrm{u} i}=\frac{n_{i}}{p_{\mathrm{a} i}} / \sum \frac{n_{i}}{p_{\mathrm{a} i}}
$$




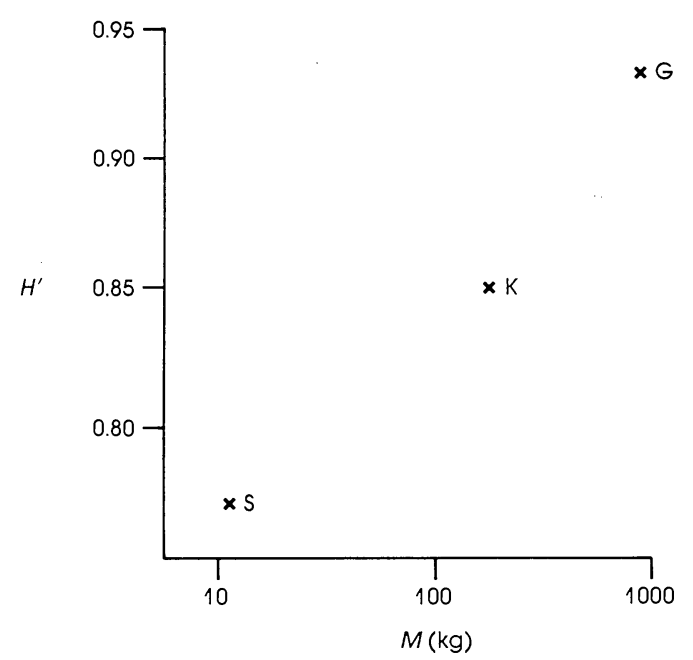

FIG. 1.-Diversity of habitat use $\left(H^{\prime}\right)$ versus body mass $(M)$ for three species of browsing ruminant: S, steenbok; K, kudu, G, giraffe. Axes are logarithmic (data from du Toit 1988).

where $p_{\mathrm{u} i}$ is the proportion of the study population using the $i$ th habitat when all habitats are equalized by area; $n_{i}$ is the mean annual number of study-animal sightings in the $i$ th habitat (using random transect counts for steenbok and radio telemetry for kudu and giraffe); and $p_{\mathrm{a} i}$ is the proportion of the study area actually covered by the $i$ th habitat. The Shannon-Wiener index $H^{\prime}$ (Shannon and Weaver 1949; Pielou 1977) was used to indicate diversity of habitat use:

$$
H^{\prime}=-\Sigma p_{\mathrm{u} i} \log p_{\mathrm{u} i} \text {. }
$$

The total number of sightings recorded per species was 349 for steenbok, 4508 for kudu, and 883 for giraffe.

The results (fig. 1) show that although all three species occurred throughout the study area, steenbok were concentrated in a narrower range of habitats than kudu, which in turn were less evenly distributed than giraffe. Although our quantitative data are limited to three species, our findings are supported by patterns of habitat use reported for other ungulate species in the Kruger National Park (Pienaar 1963; Smithers 1983). For example, klipspringer (Oreotragus oreotragus) and bushbuck (Tragelaphus scriptus) are both small ruminants (11 kg and $30 \mathrm{~kg}$ ) with specific habitat requirements; klipspringer are restricted to rocky outcrops and bushbuck to riparian thickets. Such habitat specificity is not shown by any larger ungulate.

For African savanna herbivores, we propose that wider feeding tolerance among larger species leads to the use of a wider range of habitat patches and, hence, to a more even use of environmental resources. Wider habitat use by larger species could apply to other primary consumers as a consequence of increased dietary tolerance for either a wider range in nutritional quality or a wider range of food-item sizes (May and MacArthur 1972; Schoener 1974). A similar pattern could be expected among secondary consumers as a reflection of the tendency for predator and prey sizes to be related (Rosenzweig 1966; Peters 1983). 
Diversity in habitat use by large species is, however, limited by the diversity of available habitats. Hence, our hypothesis applies to ecosystems with high spatial heterogeneity, or patchiness, and this is expected to decrease with increasing latitude as a consequence of the latitudinal gradient in ecological diversity (see Brown and Gibson 1983). The ability of larger species to feed in a wider range of habitats, together with the increased habitat diversity in tropical ecosystems, could explain a difference between the results of Peters and Raelson (1984) and those of Damuth (1987). Peters and Raelson's results show that population metabolism scales positively with body mass among mammalian herbivores in the tropics, but not if North American data are included. In contrast, Damuth's results indicate that the scaling of population metabolism in the tropics is not significantly different from the global pattern. This could be because Damuth based his study on "ecological" densities, referring to the area of habitat actually used by the animals in all cases, whereas Peters and Raelson used "crude" densities over larger areas that include some (perhaps less productive) patches unoccupied by some (perhaps smaller) species.

\section{ACKNOWLEDGMENTS}

Constructive reviews of the manuscript were made by J. H. Brown, J. Damuth, M. L. Rosenzweig, A. R. E. Sinclair, and an anonymous reviewer. The Council for Scientific and Industrial Research, South African Nature Foundation, National Parks Board, and University of the Witwatersrand provided research funds and assistance.

LITERATURE CITED

Bell, R. H. V. 1971. A grazing ecosystem in the Serengeti. Sci. Am. 225(1):86-93.

Brown, J. H., and A. C. Gibson. 1983. Biogeography. Mosby, St. Louis.

Brown, J. H., and B. A. Maurer. 1986. Body size, ecological dominance and Cope's rule. Nature (Lond.) 324:248-250.

Damuth, J. 1981. Population density and body size in mammals. Nature (Lond.) 290:699-700.

1987. Interspecific allometry in population density in mammals and other animals: the independence of body mass and energy-use. Biol. J. Linn. Soc. 31:193-246.

Demment, M. W., and P. J. van Soest. 1985. A nutritional explanation for body-size patterns of ruminant and non-ruminant herbivores. Am. Nat. 125:641-672.

du Toit, J. T. 1988. Patterns of resource use within the browsing ruminant guild in the central Kruger National Park. Ph.D. diss. University of the Witwatersrand, Johannesburg, South Africa.

Jarman, P. J. 1974. The social organisation of antelope in relation to their ecology. Behaviour 48 : 215-266.

Kleiber, M. 1961. The fire of life: an introduction to animal energetics. Wiley, New York.

May, R. M., and R. H. MacArthur. 1972. Niche overlap as a function of environmental variability. Proc. Natl. Acad. Sci. USA 69:1109-1113.

Owen-Smith, R. N. 1988. Megaherbivores: the influence of very large body size on ecology. Cambridge University Press, Cambridge.

Peters, R. H. 1983. The ecological implications of body size. Cambridge University Press, Cambridge.

Peters, R. H., and J. V. Raelson. 1984. Relations between individual size and mammalian population density. Am. Nat. 124:498-517.

Pielou, E. C. 1977. Mathematical ecology. Wiley, New York. 
Pienaar, U. de V. 1963. The large mammals of the Kruger National Park-their distribution and present-day status. Koedoe 6:1-37.

Rosenzweig, M. L. 1966. Community structure in sympatric Carnivora. J. Mammal. 47:602-612.

Schoener, T. W. 1974. Resource partitioning in ecological communities. Science (Wash., D.C.) 185:27-39.

Shannon, C. E., and W. Weaver. 1949. The mathematical theory of communication. University of Illinois Press, Urbana.

Sinclair, A. R. E. 1985. Does interspecific competition or predation shape the African ungulate community? J. Anim. Ecol. 54:899-918.

Smithers, R. H. N. 1983. The mammals of the southern African subregion. University of Pretoria, Pretoria, South Africa.

Vesey-Fitzgerald, D. F. 1960. Grazing succession among East African game animals. J. Mammal. 41:161-172.

\section{Resource Ecology Group}

DePARTMENT OF ZOOLOGY

UNIVERSITY OF THE WITWATERSRAND

P.O. WITS 2050

South Africa

Submitted April 8, 1988; Revised July 18, 1988; Accepted October 23, 1988

*Present address: Department of Range Science, Utah State University, Logan, Utah 84322-5230. 